\title{
The miracle at St Alfege's: seventy years on
}

M R Lee

J R Soc Med 2007;100:108-109

There has been much discussion in medical (and statistical) circles over the last ten years in regard to the possibility, practicality and significance of a clinical trial in which only one patient (or individual) is studied; that is, $n$ (conventionally the number studied) is equal to one.

The deficiencies of such trials are widely recognized. The patient studied may not be typical or representative of the disorder or disease under investigation. Blinding may be difficult. In a chronic disorder, the patient may be entering a natural remission which results in a false positive effect (vis medicatrix naturae; the healing power of nature). Moreover the intense interest of the physician exerted on a single individual may exert a profound placebo effect which can substantially distort the outcome.

Very occasionally, however, there is such a marked effect by the drug (or procedure) that a positive response cannot, in the end, be denied. One such is the miracle at St Alfege's Hospital Greenwich, London, as described by Mary Broadfoot Walker in her letter to the Lancet in 1934. ${ }^{1}$

First, to set the context: myasthenia gravis was at that time an incurable progressive neurological illness that resulted in double vision, muscular weakness, difficulty in swallowing and eventually respiratory paralysis. Walker reported a rapid response to physostigmine: ${ }^{1}$

'Several comments can be made about this patient's reponse to physostigmine:

- The improvement in the ptosis (lid droop) produced by the drug was dramatic;

- The effect of the drug physostigmine was dose-related in terms of the duration of the effect on the muscles, suggesting a specific antagonistic action;

- When saline and other chemical modalities were given there was no effect;

- These results tend to rule out a placebo effect (saline inactive) and to confirm the specificity of physostigmine (lack of action of ephedrine; strychnine; pilocarpine and adrenaline).'

Walker's seminal observation fell on stony ground: in short, no one took the slightest notice! In part this negative response may have been conditioned by the hypothesis that Mary Walker had put forward to explain

Correspondence to: Michael Radcliffe Lee, 112 Polwarth Terrace, Edinburgh EH11 1NN, Scotland, UK her result - namely that myasthenia gravis was caused by a circulating excess of a curariform-like chemical substance and that physostigmine temporarily reversed the effect of this poison on the motor end plates, perhaps by inhibiting acetylcholinesterase. As events would turn out, Mary Walker was correct in her observation but wrong in her inference.

Fortunately her cause was taken up by Dr Philip Hamell, a lecturer in pharmacology at St Bartholomew's Hospital Medical School, who persuaded Dr Walker to demonstrate the effect of physostigmine on a second patient with myasthenia gravis at the Clinical Section of the Royal Society of Medicine in London on 8 February 1935. At this meeting, both physostigmine and a new synthetic congener called prostigmine were shown to reverse the symptoms of myasthenia gravis substantially, albeit temporarily. ${ }^{2}$ Hamell commented during this meeting, cautiously but optimistically: 'Whatever be the mechanism of myasthenia gravis, physostigmine and its ally prostigmine reverse and overcome this defect at least for a period.' $n$ had now risen to 2 . The public demonstration at the Royal Society of Medicine stimulated widespread interest. As a result Blake Pritchard ${ }^{3}$ at the Maida Vale Hospital and LPE Laurent ${ }^{4}$ at University College Hospital reported small series of patients, all of whom had responded positively (seven cases and seven cases respectively). $n$ had risen to 16 !

The phenomenon of physostigmine reversal now seemed to be well-established and the message jumped the Atlantic. The first patient was treated in April 1935 at the Massachusetts General Hospital in Boston and subsequently a Myasthenia Gravis Clinic was established there. This clinic later became world-famous in the diagnosis and treatment of this rare but devastating neurological illness. Viets and Schwab $^{5}$ designed and standardized a diagnostic test for the disease using prostigmine. Later, another quaternary derivative was employed for diagnosis - edrophonium, a shorter acting, safer compound.

The question remained as to the nature of 'the Walker effect'. Some twelve months later, in 1936, Sir Henry Dale and his colleagues Feldberg and Vogt demonstrated that acetylcholine was indeed the transmitter at the neuromuscular junction of mammals. Moreover, physostigmine (and prostigmine) prolonged the action of the released ester by inhibiting the enzyme acetylcholinesterase, which usually brought transmission to an end by destroying this ester of choline. 
In myasthenia gravis, some mechanism was blocking either the production or the action of acetylcholine at the motor endplate. Was it, as Walker had suggested, curare or a curare-like substance? The answer we now know is in the negative. Autoantibodies produced by T lymphocytes bind to the motor end plates and prevent the depolarizing effect of the released acetylcholine. To demonstrate this pathological mechanism would take another fifty years.

Nevertheless, Walker's leap into the darkness with an inadequate $n=1$ trial had demonstrated that myasthenia gravis could be treated with physostigmine, and this observation would prove important and robust. Moreover it would lead, with the work of Dale and other investigators, to the conclusion that acetylcholine was indeed the transmitter at the 'nicotinic' receptors in muscle. This discovery was of overarching significance, as it had been disputed for years. It had consequences that would lead on to the present day in the manufacture (and use) of 'nerve gases' such as the organophosphates, which attack the motor end plate.

Mary Walker remained in the background after her momentous observation. ${ }^{6}$ She never received a Fellowship of a Royal College of Physicians and never occupied a teaching hospital post. Having retired to her native Scotland she died in comparative obscurity at Wigtown in Dumfriesshire in 1974 at the advanced age of 86 years. Nevertheless she had made, with her $n=1$ trial, one of the greatest clinical observations of the twentieth century. Despite much initial scepticism, anticholinesterase drugs such as physostigmine (and its modern congeners) have become a cornerstone in the treatment of myasthenia gravis. A shy, self-effacing individual, her leap of faith, though founded on a false proposition, has served to transform the lives of sufferers from myasthenia gravis the world over.

\section{REFERENCES}

1 Walker MB. Treatment of myasthenia gravis with physostigmine. Lancet 1934;1:1200-1

2 Walker MB. The action of physostigmine and 'Prostigmin' in the treatment of myasthenia gravis. Proc Roy Soc Med 1935;28:759-60

3 Blake Pritchard EA. The use of 'Prostigmin' in the treatment of myasthenia gravis. Lancet 1935;1:432-4

4 Laurent LPE. Clinical observations on the use of prostigmin in the treatment of myasthenia gravis. BMJ 1935;1:463-6

5 Viets HR, Schwab RS. Prostigmin in the diagnosis of myasthenia gravis. N Engl J Med 1935;213:1280-2

6 Viets HR. The Miracle at St. Alfege's. Medical History 1965;9:184-5 